Elsevier required licence: (c) 2016. This manuscript version is made available under the CC-BY-NC-ND 4.0 license http://creativecommons.org/licenses/by-nc-nd/4.0/ 


\title{
Further investigations into the single metal deposition (SMD II) technique for the detection of latent fingermarks
}

\author{
Talia G. Newland ${ }^{1,2}$, Sebastien Moret $^{3}$, Andy Bécue ${ }^{4}$, Simon W. Lewis ${ }^{1,2^{*}}$ \\ ${ }^{1}$ Nanochemistry Research Institute, Curtin University, GPO Box U1987, Perth, Western \\ Australia 6845, Australia. \\ ${ }^{2}$ Department of Chemistry, Curtin University, GPO Box U1987, Perth, Western Australia \\ 6845, Australia.
}

${ }^{3}$ Centre for Forensic Science, University of Technology Sydney, PO Box 123, Broadway, NSW 2007, Australia

${ }^{4}$ École des Sciences Criminelles / School of Criminal Justice, Building Batochime, University of Lausanne, CH-1015 Lausanne (Switzerland)

*Author for correspondence, Email: s.lewis@curtin.edu.au

\begin{abstract}
Single metal deposition (SMD II), a recently proposed method for the development of latent fingermarks, was investigated by systematically altering aspects of the procedure to assess their effect on the level of development and contrast achieved. Gold nanoparticle size, temperature of the deposition solution bath, and orbital shaking during detection were shown to affect the levels of development and contrast obtained. Gold nanoparticles of diameter 15-21 nm were found to be most effective for satisfactory visualisation of latent fingermarks, while solutions that were applied at room temperature were found to adequately balance the ratio between the contrast of the fingermark ridge detail and the level of background staining achieved. Finally, optimum levels of development and contrast were obtained through constant agitation of both solution baths at approximately 50 RPM throughout the submersion time. SMD II was also tested on a large variety of substrate types and shown to be effective on a range of porous, non-porous, and semi-porous surfaces; however, the detection quality can be significantly influenced by the substrate nature. This resulted in the production of dark grey, white, or gold coloured fingermarks on different surfaces, as well as reversed detection on certain types of plastic, similarly seen through the use of vacuum metal deposition.
\end{abstract}

\section{Keywords}

fingermark development; gold nanoparticles; nanotechnology; substrates 


\section{Introduction}

Interest in nanoparticles for fingermark detection has gained a lot of momentum since early 2000 due to the many potentially beneficial properties they exhibit (1-3). Nanoparticles are extremely small in diameter, generally 1000 - 10000 times smaller than a fingermark ridge width, ensuring excellent resolution upon detection $(1,4)$. The properties of nanoparticles can be modified easily by the addition of molecular chains or chemical functionalities on their outer surface (5-7), ensuring the specific targeting of fingermark components $(1,4,8)$. They can also exhibit various optical properties due to the presence of surface plasmons, and allow for the possibility of luminescence depending on the type of nanoparticle $(1,4,8$ 10). This can effectively increase the sensitivity of detection techniques based on such materials $(8,11)$.

Single metal deposition (SMD II) is considered the latest improvement of the original multimetal deposition (MMD) technique, and uses gold for both the deposition and enhancement stages (12-16). This development technique involves the deposition of citratereduced gold nanoparticles onto fingermark ridges in a colloidal gold solution bath, and then reduction of additional gold in a reinforcement solution bath for further contrast enhancement (Figure 1) (13-16).

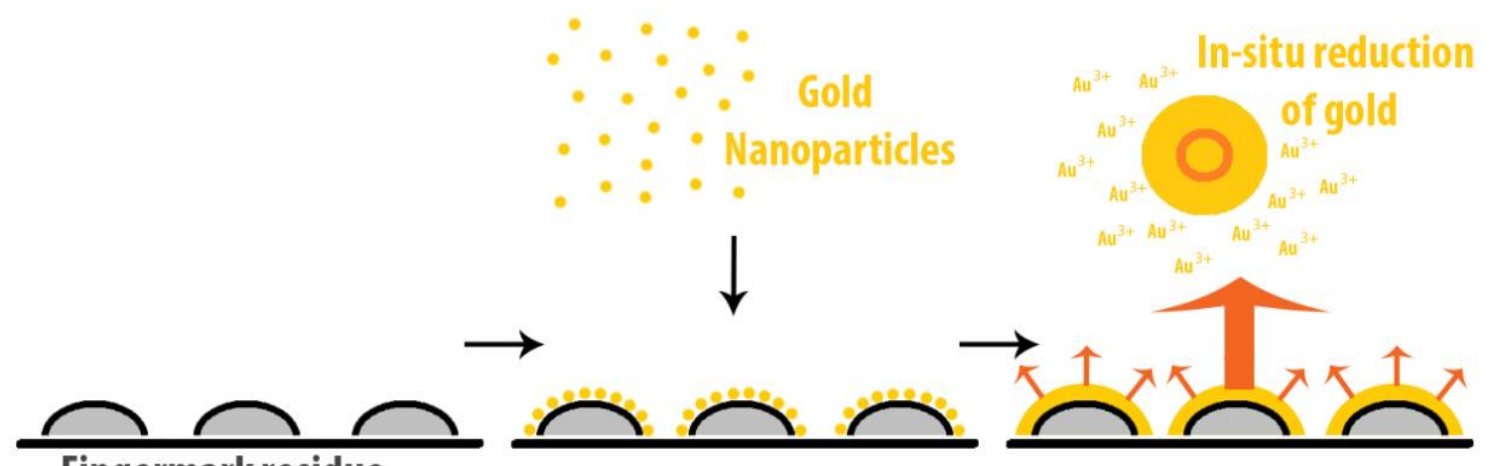

\section{Fingermark residue}

Figure 1: The development process of single metal deposition performed on latent fingermark residue, involving a deposition step followed by a reduction step, adapted from Bécue, 2010 (17).

The colloidal gold deposition bath also contains a citric acid buffer, Tween 20 (surfactant) to prevent nanoparticle aggregation, and a small amount of L-aspartic acid, which is expected to replace a minor portion of the gold nanoparticle surface functionalisation to allow for efficacy of the method across a much wider $\mathrm{pH}$ range $(12,16)$.

This evolution of the technique was proven to be more efficient and robust than previous ones, allowing development of a larger number of samples in one solution bath with significantly less impact on the quality of the mark, and detecting $50 \%$ more fingermarks (16). There is no need to monitor the $\mathrm{pH}$ of the working solutions as with other methods, and the synthetic protocol has been optimised to generate $2.5 \mathrm{~L}$ of solution, making it extremely suited to operational use (16). SMD II is believed to work on most surface types, 
including adhesives, cartridge cases, and even wetted items, for latent fingermarks up to and possibly older than -2 years old $(13,16)$.

The standardisation and validation of newly proposed fingermark detection methods is extremely important for strengthening fingermark research and improving operational detection capabilities, therefore, the overall purpose of this study was to investigate the novel SMD II method for latent fingermark detection with respect to the International Fingerprint Research Group (IFRG) Guidelines (18). The environmental conditions in which a fingermark development procedure is performed can have a significant impact on its efficacy, such as in the case of 1,2-indanedione. Prolonged heating in low humidity conditions can result in the formation of non-fluorescent oligomeric by-products, while exposure to high humidity during the development or subsequent storage of samples can result in the degradation of Joullié's Pink back to 1,2-indanedione or a hydrindantin derivative (19-21).

As it can be seen from the literature, most of the MMD/SMD optimisation studies were performed in Switzerland, the climate of which can be described as moderate, with no excessive heat, cold, or humidity $(18,22,23)$. Climatic conditions in Western Australia vary from those of Switzerland in terms of both average temperature and humidity, with the south-west region in particular experiencing hot, dry summers and mild, wet winters (24, 25). For this reason, the procedure was firstly tested for its reliability and robustness under Western Australian conditions, and on a range of different substrates. The protocol was also subjected to systematic experimentation with several different parameters in accordance with Phase 2 of the IRFG Guidelines - 'Optimisation \& Comparison' (18). This can provide knowledge as to which conditions are crucial for successful detection of latent fingermarks using a particular method, and assist forensic investigators in achieving optimum levels of development. The main areas of interest to be examined were the effect of nanoparticle size, temperature, and agitation of the solution baths.

\section{Materials and Methods}

Tetrachloroauric acid trihydrate, trisodium citrate dihydrate, sodium hydroxide, L-aspartic acid, Tween 20, citric acid monohydrate, and hydroxylamine hydrochloride were all sourced from Sigma-Aldrich, USA. Reagents were of analytical grade and used as received, and water utilised was deionised unless otherwise stated.

\subsection{Fingermark samples}

Latent fingermarks were collected from five donors (three male and two female, all aged between 20-29 years) for each trial over the duration of the testing period. For each substrate considered in this study, the donors were asked to lightly touch the middle three fingers of each hand to leave 'uncharged' or natural fingermark samples. They then rubbed the fingers of both hands over their faces and chests to 'charge' their fingers with sebum 
before repeating the above deposition process. For substrate testing there were 23 substrates and 30 marks per substrate ( 3 charged and 3 uncharged marks from 5 donors) giving a total of 690 marks. For the studies into nanoparticle size, effect of temperature, and shaking there were 72 marks for each of the 3 studies ( 6 charged and 6 uncharged marks from 5 donors) giving a total of 180 marks. Each donor was allocated an anonymous alphanumeric code for recording purposes. Fingermarks were then stored in paper envelopes and placed in an office cupboard at room temperature for 1-2 weeks before treatment, unless otherwise stated. For comparison studies, all samples were cut in half down the middle finger immediately prior to their development to provide two alike samples. This 'split-mark' approach has been recommended by the IFRG, and in articles dealing with fingermark deposition protocols for detection purposes $(18,26,27)$.

\subsection{Colloidal gold solution synthesis}

The stock solutions for SMD II were prepared according to the method published by Moret and Bécue (16). Their contents were as follows:

Table 1: Stock solutions prepared for the SMD II development procedure.

\begin{tabular}{|c|c|}
\hline Solution A & \begin{tabular}{c}
0.500 g tetrachloroauric acid trihydrate dissolved in $5 \mathrm{~mL}$ Milli-Q water \\
\hline Solution B
\end{tabular} \\
\hline Solution C & $\begin{array}{r}\text { 1.70 g trisodium citrate dihydrate dissolved in } 85 \mathrm{~mL} \text { Milli-Q water } \\
\text { Milli-Q water }\end{array}$ \\
\hline Solution D & 31.5 g citric acid monohydrate dissolved in $150 \mathrm{~mL}$ Milli-Q water \\
\hline Solution E & $1.00 \mathrm{~g}$ hydroxylamine hydrochloride dissolved in $50 \mathrm{~mL}$ Milli-Q water \\
\hline
\end{tabular}

Solution $A$ was stored in a sample vial in a refrigerator at $4{ }^{\circ} \mathrm{C}$ to prolong its shelf-life, while solutions B-E were stored at room temperature in glass bottles in a cupboard away from light.

Colloidal gold was prepared as follows (17): solution A (1 mL) was added to deionised (DI) water $(460 \mathrm{~mL}$ ) and heated to boiling point under constant stirring (solution 1$)$. In a separate beaker, solution $B(42 \mathrm{~mL})$ was combined with solution $C(420 \mu \mathrm{L})$. When solution 1 reached its boiling point, the content of the beaker was quickly poured in. The solution continued to be heated under constant stirring until it turned a deep red colour, at which point it was diluted with DI water to reach a final volume of $2.5 \mathrm{~L}$. Tween $20(2.5 \mathrm{~mL})$ was then added under stirring. The solution was stored in a polypropylene container in a refrigerator at $4{ }^{\circ} \mathrm{C}$. For every application of SMD II, a red-coloured gold nanoparticle stock solution synthesised according to this method was used, unless otherwise stated. 
Several versions of gold nanoparticle stock solution were synthesised that contained gold nanoparticles of different diameters, labelled stock \#1 (original), and stocks \#2 to \#4 (derivatives). This was carried out by following the method outlined above, but altering the length of the boiling time of solution 1 prior to adding the reducing agents: under 1 minute of boiling time (stock \#2), 5 or more minutes of boiling time (stock \#3), and 1-2 minutes of boiling time (stock \#4). The nanoparticle diameters within all these solutions were later measured using dynamic light scattering (DLS).

\subsection{Nanoparticle characterisation}

All gold nanoparticle stock solutions were analysed in $1 \mathrm{~cm}$ optical path cells and characterised using an Agilent Cary Series 4000 UV-Vis spectrophotometer across wavelengths of $400-800 \mathrm{~nm}$. DI water was used as a blank reference sample. Data acquisition and processing was performed using Cary WinUV software (version 4.20).

DLS size analysis of all gold stock solutions was performed using the same standard operating procedure set at $20^{\circ} \mathrm{C}$, with the original stock solution \#1 also being analysed at temperatures ranging from $10-30{ }^{\circ} \mathrm{C}$. The measurements were performed using a Malvern Zetasizer Nano ZS (model ZEN3600) with a $1 \mathrm{~cm}$ optical path cell. A minimum 10 scans were performed per sample before producing a value. Malvern Zetasizer Nano software (version 7.11) was utilised for data acquisition.

\subsection{Fingermark detection}

The detection of fingermarks was conducted as follows (17): gold nanoparticle stock solution $(200 \mathrm{~mL})$ was removed from the refrigerator and left to warm up to room temperature in a glass dish. $6 \mathrm{~mL}$ of solution $\mathrm{D}$ were then added under constant stirring to lower the $\mathrm{pH}$ of the solution ( $3 \mathrm{~mL}$ for every $100 \mathrm{~mL}$ of stock solution). Fingermark samples were submersed in DI water for 2-3 minutes before being submersed in the gold nanoparticle solution bath for 20 minutes under constant orbital shaking on a PathTech Basic Orbital Mixer at approximately 50 RPM (Figure 2). Samples were then rinsed in DI water for 2-3 minutes. In another glass dish, solution $A(200 \mu \mathrm{L})$ and solution $E(200 \mu \mathrm{L})$ were added to DI water $(200 \mathrm{~mL})$ under intense stirring to form a reduction bath. Samples were then submersed in this reduction bath for 20 minutes under constant orbital shaking at approximately 50 RPM. They were then rinsed in DI water again for 2-3 minutes before being left to dry on paper towels at room temperature.

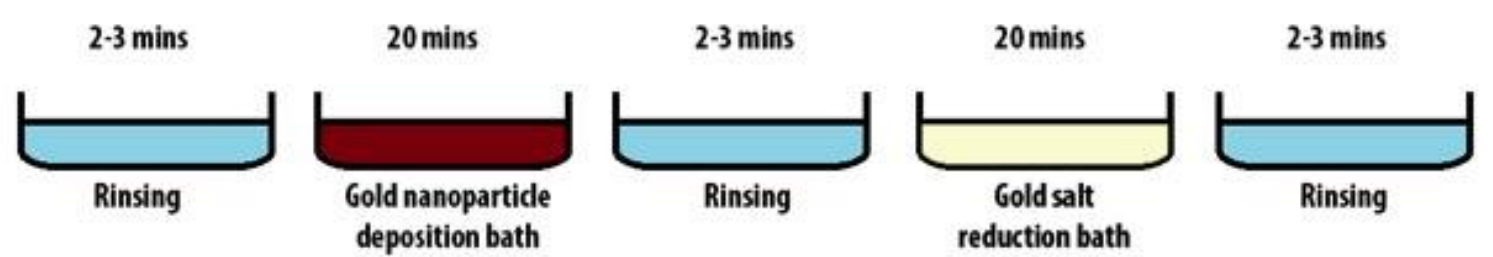


To investigate the effect of nanoparticle size on the development of latent fingermarks, several gold stock solutions that contained nanoparticles of different diameters (stocks \#1 to \#4) were applied to fingermarks using the SMD II procedure. Overlooking the size of the gold nanoparticles, these solutions were similar to the original gold nanoparticle stock solution, and were applied in the same way to split-mark samples (stock solution \#1 vs \#2, and \#3 vs \#4).

The effect of the temperature of the gold nanoparticle solution bath on the development of latent fingermarks was investigated through the application of portions of the best-suited gold stock solution to fingermark samples at different temperatures; straight from the refrigerator at $4{ }^{\circ} \mathrm{C}$, at a room temperature of $20^{\circ} \mathrm{C}(\mathrm{RT})$, and heated to $30{ }^{\circ} \mathrm{C}$ immediately prior to the submersion of samples. These solutions were similar to each other in composition and appearance and, except for their temperature, were applied in the same way to split-mark samples (RT vs $4{ }^{\circ} \mathrm{C}$, and RT vs $30^{\circ} \mathrm{C}$ ).

To investigate how agitation of the solution baths affects the development of latent fingermarks using SMD II, the method was carried out several times with the solution baths under different levels of agitation; constant agitation of both active solution baths for the entire submersion time, minimal agitation (30 second shake at the beginning, middle, and end of the submersion time for each bath), and no agitation at all. Trials were also done where only the gold nanoparticle solution bath was under constant agitation for the entire submersion time, while the reduction bath experienced no agitation at all. The agitation was kept steady throughout the procedure by using a PathTech Basic Orbital Mixer set at approximately 50 RPM. These nanoparticle solutions were all taken from one batch of the original gold nanoparticle stock solution (\#4) and were therefore identical to each other. Excluding the level of agitation, these solutions were applied in exactly the same way to split mark samples (no agitation vs minimal agitation vs full agitation, and full procedure agitation vs only colloidal gold agitation).

\subsection{Substrates}

In order to assess the efficacy of the SMD II procedure on different surfaces, latent fingermarks were collected on 23 different substrates, as listed in Table 2. 
Table 2: List of the substrates considered in this study.

\begin{tabular}{|c|c|c|}
\hline Substrate & Type & Manufacturer/Product \\
\hline Recycled white copy paper & Porous & OfficeMax ${ }^{\circledR} 50 \%$ recycled paper \\
\hline $\begin{array}{l}\text { Calcium carbonate-chalk / } \\
\text { polyethylene blend paper }\end{array}$ & Porous & Nu World ${ }^{\circledR}$ Stone Paper \\
\hline $\begin{array}{c}\text { Transparent polypropylene } \\
\text { document sleeve }\end{array}$ & Non-porous & Marbig $^{\circledR}$ \\
\hline White copy paper & Porous & $\begin{array}{c}\text { Fuji Xerox }{ }^{\circledR} \text { Business Digital Carbon } \\
\text { Neutral }\end{array}$ \\
\hline Glass microscope slide & Non-porous & $\begin{array}{c}\text { Mikro }^{\circledR} \text { optical quality microscope } \\
\text { slides }\end{array}$ \\
\hline Aluminium foil (matte side) & Non-porous & Confoil $^{\circledR}$ heavy duty \\
\hline Aluminium can & Non-porous & Coke Zero $^{\circledR}$ \\
\hline $\begin{array}{l}\text { Polycarbonate Compact Disk } \\
\text { (recording side) }\end{array}$ & Non-porous & Lite-On ${ }^{\circledR}$ \\
\hline Polyethylene bottle & Non-porous & Kartell $^{\circledR} 500$ mL laboratory bottle \\
\hline Polyethylene terephthalate bottle & Non-porous & Cool Ridge ${ }^{\circledR} 600 \mathrm{~mL}$ water bottle \\
\hline Polypropylene takeaway container & Non-porous & Unknown Manufacturer \\
\hline $\begin{array}{l}\text { Polymethyl methacrylate white car } \\
\text { paint sample }\end{array}$ & Non-porous & Paint taken from a Holden VF GTS \\
\hline White Post-It note & Porous & Post It ${ }^{\circledR}$ \\
\hline Thick cardboard & Porous & Curtin University document wallet \\
\hline Ruled graph paper & Porous & Gormack Graph Papers ${ }^{\circledR}$ \\
\hline Glossy white paper & Semi-porous & $\begin{array}{l}\text { International Association for } \\
\text { Identification's "IDentification } \\
\text { News" newsletter }\end{array}$ \\
\hline Smooth white paper & Porous & $\begin{array}{c}\text { American Academy of Forensic } \\
\text { Sciences' "Academy News" } \\
\text { newsletter }\end{array}$ \\
\hline Lined thin white paper & Porous & Olympic $^{\circledR}$ exercise book \\
\hline Lined thick white paper & Porous & Spank Publishing ${ }^{\circledR}$ notebook \\
\hline White matte photo paper & Semi-porous & HP ${ }^{\circledR}$ Photo Laser Paper 200 matte \\
\hline Black cardboard & Porous & Optix $^{\circledR}$ Jetz Black \\
\hline Green copy paper & Porous & Optix $^{\circledR}$ Veni Green \\
\hline Patterned wrapping paper & Porous & Unknown manufacturer \\
\hline
\end{tabular}

All plastic substrates were characterised through attenuated total reflectance infrared (ATRIR) analysis on a Thermo Scientific Nicolet iS50 Fourier transform infrared (FT-IR) spectrometer (see Supplementary Material Figures A1-6). The Nu World ${ }^{\circledR}$ Stone Paper was selected as the substrate for the majority of experimentation within this research, unless otherwise stated. 


\subsection{Recording and evaluation of results}

Samples were photographed using a Nikon D300 camera, equipped with a $28 \mathrm{~mm}$ AF-S Micro-Nikon lens, mounted overhead on a Firenze Mini Repro stand and acquired on a computer using Nikon Camera Control Pro version 2.0.0. Samples photographed in reflectance mode were illuminated using dual incandescent light globes mounted on either side of the camera. Photographed samples were then stored in paper envelopes in a laboratory cupboard at room temperature. All images were later adjusted for brightness and contrast using Adobe Photoshop CS6 version 13.0, with any adjustments applied equally to all equivalent sample photographs.

All treated fingermarks were graded by a single evaluator based on the quality of friction ridge detail developed, and the contrast between the fingermark ridges and background of the sample. A 5-point system developed by the UK Home Office Centre for Applied Science and Technology (CAST) was used, as per Table 3 (28).

Table 3: UK Home Office grading system used to classify developed fingermarks (28).

\begin{tabular}{|c|c|}
\hline Grade & Level of Development \\
\hline $\mathbf{0}$ & No development \\
\hline $\mathbf{1}$ & Signs of contact but less than $1 / 3$ of continuous ridges, poor contrast \\
\hline $\mathbf{2}$ & $1 / 3-2 / 3$ of continuous ridges, adequate contrast \\
\hline $\mathbf{3}$ & More than $2 / 3$ of continuous ridges but not quite a 'perfect' fingermark, good contrast \\
\hline $\mathbf{4}$ & Full development; whole fingermark, continuous ridges, excellent contrast \\
\hline
\end{tabular}

These allocated grades should be considered as nonparametric class identities rather than continuous values. For this reason, the most frequently occurring fingermark grade (mode) was calculated for each trial and used as a means of comparison between samples. When trials resulted in equivalent modes, the central fingermark grade obtained (median) was also provided for a more detailed indication of the distribution of the grades (29).

\section{Results and Discussion}

\subsection{Colloidal gold nanoparticle synthesis and characterisation}

When synthesising gold nanoparticles for the SMD II stock solution according to the method published, it was found that the length of the boiling time of the gold salt in water had a significant effect on the size of the nanoparticles being produced, and therefore the colour of the solution. If the reducing agents were added immediately upon boiling (stock \#2), nanoparticles with a larger diameter than intended were produced, resulting in a dark 
purple coloured solution (Figure 3). If the reducing agents were added after a minute or two of boiling (original stock \#1 and \#4), nanoparticles of the intended size were produced, resulting in the desired red solution. If the reducing agents were added after approximately 5 or more minutes of boiling (stock \#3), nanoparticles of a much smaller diameter were produced, resulting in a grey coloured solution.

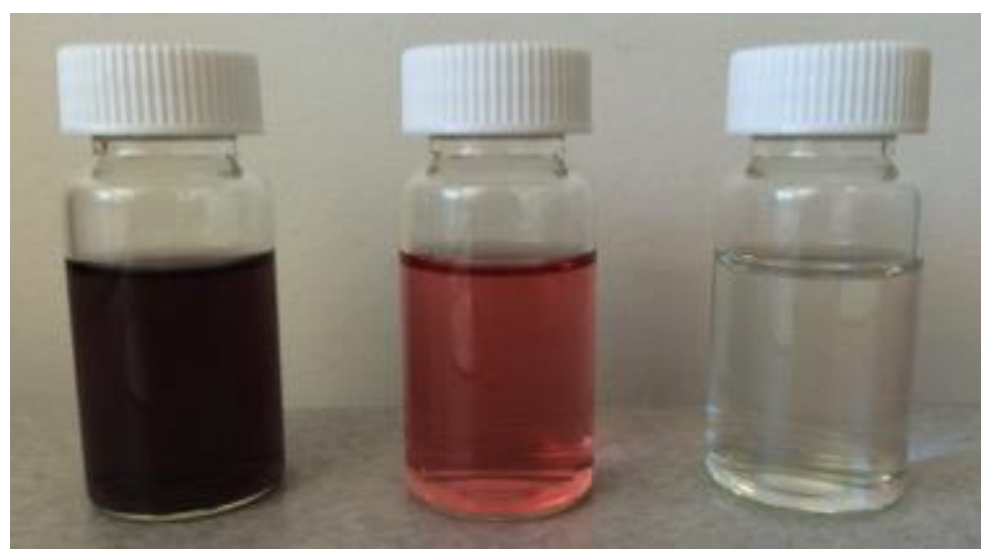

Figure 3: SMD II gold nanoparticle stock solutions \#2 (left), \#1 (middle), and \#3 (right) containing different sized nanoparticles, with the length of the boiling time increased in samples from left to right.

The nanoparticle diameters were measured for the four different colloidal gold stock solutions using DLS after their dilution and the addition of Tween 20, with the results outlined in Table 4.

Table 4: Characterization of the different colloidal gold solutions in terms of colour and diameter size (measured by dynamic light scattering).

\begin{tabular}{|c|c|c|}
\hline $\begin{array}{c}\text { Gold Nanoparticle } \\
\text { Stock Solution }\end{array}$ & Colour of Solution & Nanoparticle Diameter \\
\hline Stock \#3 & Grey & $6 \mathrm{~nm}$ \\
\hline Stock \#4 & Red & $17 \mathrm{~nm}$ \\
\hline $\begin{array}{c}\text { Stock \#1 - } \\
\text { "Reference" }\end{array}$ & Red & $21 \mathrm{~nm}$ \\
\hline Stock \#2 & Dark purple & $34 \mathrm{~nm}$ \\
\hline
\end{tabular}

The reference solution ( $21 \mathrm{~nm}$ ) that was synthesised by following the published method resulted in nanoparticles with a slightly larger diameter than those obtained by Bécue et al. $(17 \mathrm{~nm})(12,16)$. For this reason stock solution \#4 $(17 \mathrm{~nm})$ was utilised for all subsequent investigations. Exact boiling times utilised to produce these individual solutions could not be determined, as it was a varying parameter based on conditions such as the initial 
temperature of the solutions and the quantity of solution being heated. Each individual gold nanoparticle stock solution was characterised by UV-visible spectroscopy (Figure 4).

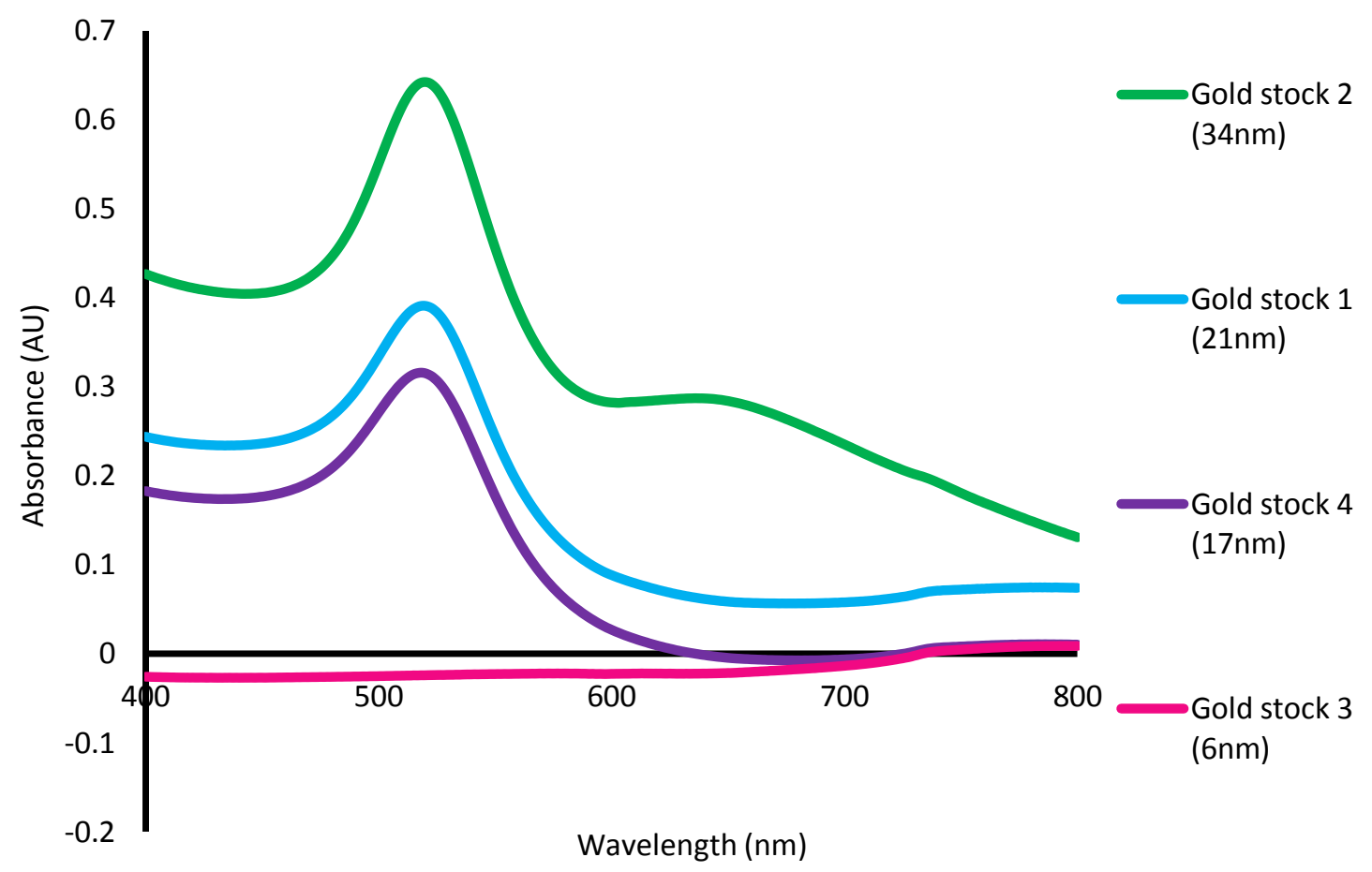

Figure 4: Absorbance spectra of the different colloidal gold solutions.

As the size of the gold nanoparticles increased, the absorbance peaks were broadened due to the increased scattering of light and variation in surface plasmon resonance (30-33). For nanoparticle diameters above $30 \mathrm{~nm}$, another smaller, broader peak started to appear at longer wavelengths resulting in two absorbance maxima, caused by the presence of both transversal and longitudinal surface plasmon resonances $(32,33)$. The purple appearance of the solutions was produced by the additional absorption at these longer wavelengths of light. Gold nanoparticle solutions consisting of smaller diameter nanoparticles, such as stock \#3 (containing $6 \mathrm{~nm}$ particles), can sometimes be too small to exhibit surface plasmon resonance, therefore resulting in no apparent absorbance of visible light (33). The spectrum produced by this solution above appeared to have negative values for its absorbance, which can most likely be attributed to an error in the background correction.

\subsection{SMD II assessment guidelines}

Guidelines for the assessment of fingermark detection techniques have been proposed by the IFRG that outline methods for the development and evaluation of new fingermark treatments (18). To ensure assessment of the naturally occurring variation in fingermark composition, these guidelines state that pilot studies of novel fingermark treatments should entail the use of samples from at least 3 donors (18). While previous publications have focussed on an actual assessment of the efficiency of the SMD and MMD development techniques, the emphasis of this study was put on the effect of the different parameters on 
the detection quality of the published SMD II protocol. For this reason, the required number of donors was consequently less important than in a sensitivity or efficiency study.

There will always be a degree of variability throughout samples; although conditions have been kept as constant as possible throughout the experiments. All donors gave samples under similar conditions within 24 hours of each other, all samples were stored in similar environmental conditions (unless otherwise stated), and the same donors were used in each trial to allow for direct comparison. As it is unlikely that fingermarks at a crime scene will be processed while still fresh, fingermark samples were stored for at least 1 week prior to treatment, unless stated otherwise. Furthermore, both natural fingermarks as well as fingermarks 'charged' with sebaceous material from the face were used throughout this research. This was done in order to replicate the use of the fingermark treatment under operational conditions, while also obtaining some form of consistency throughout samples.

\subsection{Effect of the nanoparticle size}

Gold nanoparticle stock solutions containing different sized nanoparticles were applied to latent fingermarks using the SMD II procedure, and resulted in varying levels of development and contrast, as evident in Figure 5.

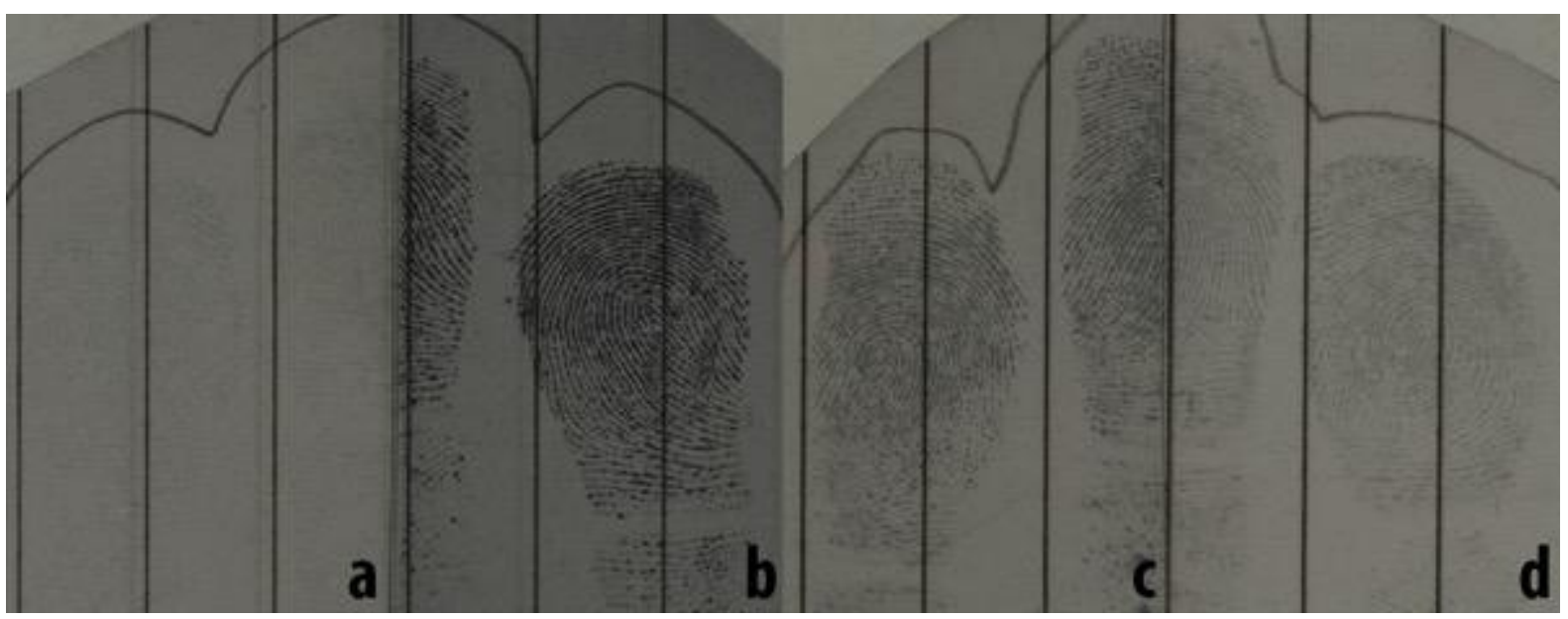

Figure 5: Latent fingermarks developed on Nu World Stone Paper using SMD II with solutions containing gold nanoparticles of diameter (a) $6 \mathrm{~nm}$, (b) $17 \mathrm{~nm}$, (c) $21 \mathrm{~nm}$, (d) $34 \mathrm{~nm}$.

The application of $6 \mathrm{~nm}$ gold nanoparticles resulted in low levels of fingermark development and minimal contrast achieved, with fingermarks most frequently being graded at 1 . Increasing the nanoparticle diameter to $17 \mathrm{~nm}$ resulted in elevated levels of fingermark development with high contrast attained against the surface, causing a fingermark grade of 3 to be produced by the majority of samples. Similar results were obtained through the use of $21 \mathrm{~nm}$ gold nanoparticles, achieving comparable levels of development with only slightly reduced contrast of the fingermark, maintaining the mode of 3 . When the nanoparticle diameter was increased further to $34 \mathrm{~nm}$, there was a significant reduction in the level of contrast achieved, as well as a slight deterioration in the degree of development. These 
samples most frequently produced a fingermark grade of 2 . The level of development and contrast obtained through the use of SMD II is heavily dependent on both the deposition of the gold nanoparticles onto the fingermark residue, as well as the reduction of gold salt induced by the already deposited nanoparticles. Smaller nanoparticles, such as those at $6 \mathrm{~nm}$, may be too small to seed satisfactory reduction of the gold salt in the reinforcement bath, resulting in what appears to be hindered levels of detection of the fingermark residue. On the opposite end of the spectrum, larger nanoparticles tend to be less surface-active than smaller particles due to the decreased surface area-volume ratio (34). Due to the reduction in surface activity of these larger nanoparticles, such as those at $34 \mathrm{~nm}$, the strength of their interactions with the fingermark residue may be minimised, resulting in smaller amounts of gold nanoparticles being deposited onto the ridge detail. This conclusion is consistent with the previous observations made by Schnetz and Margot that nanoparticles of diameters larger than $20 \mathrm{~nm}$ result in inhibited deposition of gold onto the fingermark when applied within the MMD procedure (35). It is evident from these results that gold nanoparticles of approximate diameter $15-21 \mathrm{~nm}$ are optimal for producing high levels of latent fingermark development and contrast, and these nanoparticle sizes are obtained through the synthesis of colloidal gold solutions that appear red. By definition of the UK Home Office fingermark grading system, the two stock solutions containing nanoparticles within this range and therefore exhibiting the desired red colour were the only samples to achieve grades indicating fingermarks that could be used operationally as a means of identification.

\subsection{Effect of the solution temperature}

Altering the temperature of the SMD II gold nanoparticle stock solution \#4 (17 nm) before the addition of citric acid and the application to latent fingermarks resulted in varying levels of development and contrast, as evident in Figure 6.

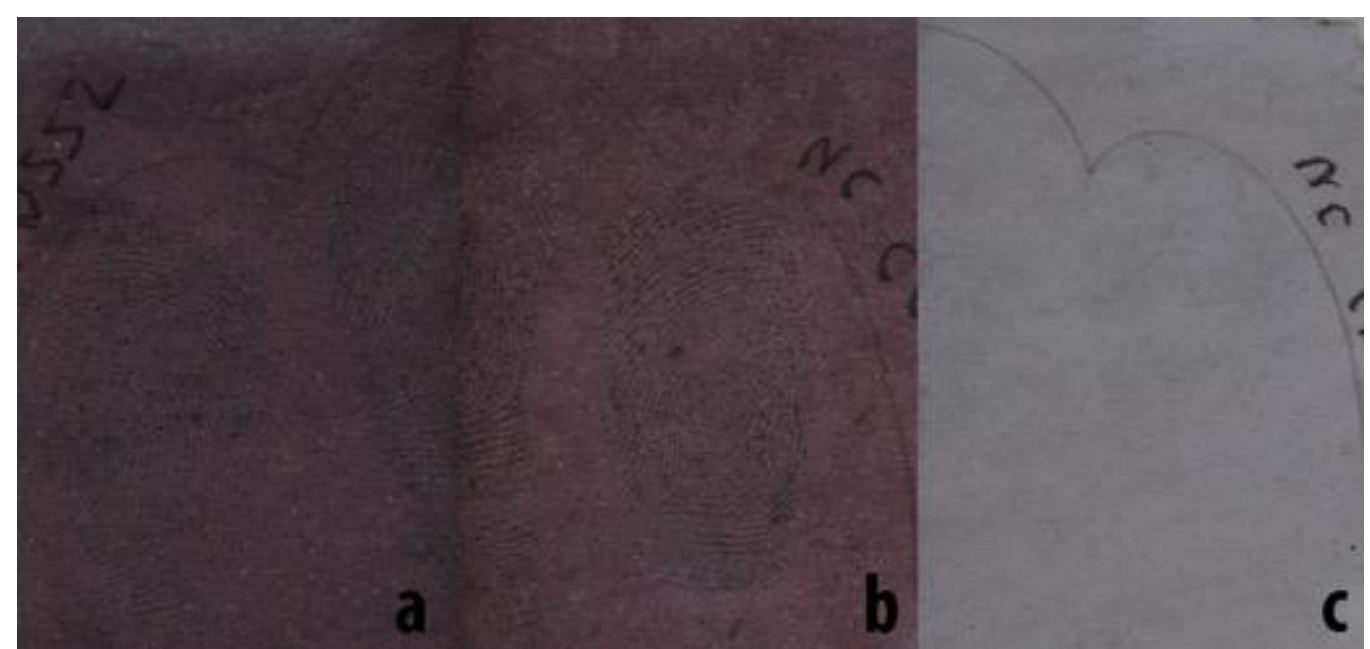

Figure 6: Latent fingermarks developed on Fuji Xerox white copy paper using SMD II with the gold nanoparticle solution bath at (a) $4^{\circ} \mathrm{C}$, (b) $20^{\circ} \mathrm{C}$, (c) $30^{\circ} \mathrm{C}$. 
Gold nanoparticle stock solutions that were applied at $4{ }^{\circ} \mathrm{C}$, immediately after removal from the refrigerator, resulted in a heavy degree of background staining. This made it difficult to observe the developed fingermarks on the surface, with the majority of these samples resulting in a grade of 0 . By allowing the solution to warm up to room temperature before application, as recommended in the proposed SMD II method, the level of background staining is decreased enough to allow visualisation of the fingermark on the substrate, with most samples giving an increased grade of 1 . Stock solutions heated to $30{ }^{\circ} \mathrm{C}$ resulted in a significant reduction in background staining, but also experienced a large decrease in the contrast of the fingermark ridge detail, again making it difficult to visualise on the substrate. The majority of heated samples obtained a grade of 1 , although the median was only 0.5 in comparison to a median of 1 for room temperature solution samples. From this data it is evident that room temperature solutions improved the ratio between the level of background staining and the contrast achieved to allow for the best possible visualisation of latent fingermarks. While these results contrast the observations made by Schnetz and Margot in regards to the effect that temperature has on the MMD development process, their conclusions once again support that room temperature solutions allow for optimisation of the procedure (35). When analysing the gold nanoparticles using DLS, trials were done at different temperatures to see if this had any notable effect on the size of the nanoparticles in solution. Heating the gold nanoparticles over $25{ }^{\circ} \mathrm{C}$ before analysis caused an apparent doubling in the nanoparticle diameter, indicating that aggregation takes place at these higher temperatures. Aggregation of the gold nanoparticles affects their ability to deposit onto the fingermark residue, resulting in inhibited development of latent fingermarks using SMD II.

\subsection{Effect of the bath agitation}

The degree of agitation imposed on both the gold nanoparticle solution bath (based on stock \#4) and the reduction solution bath significantly affects the level of latent fingermark development and contrast achieved, as seen in Figure 7. 


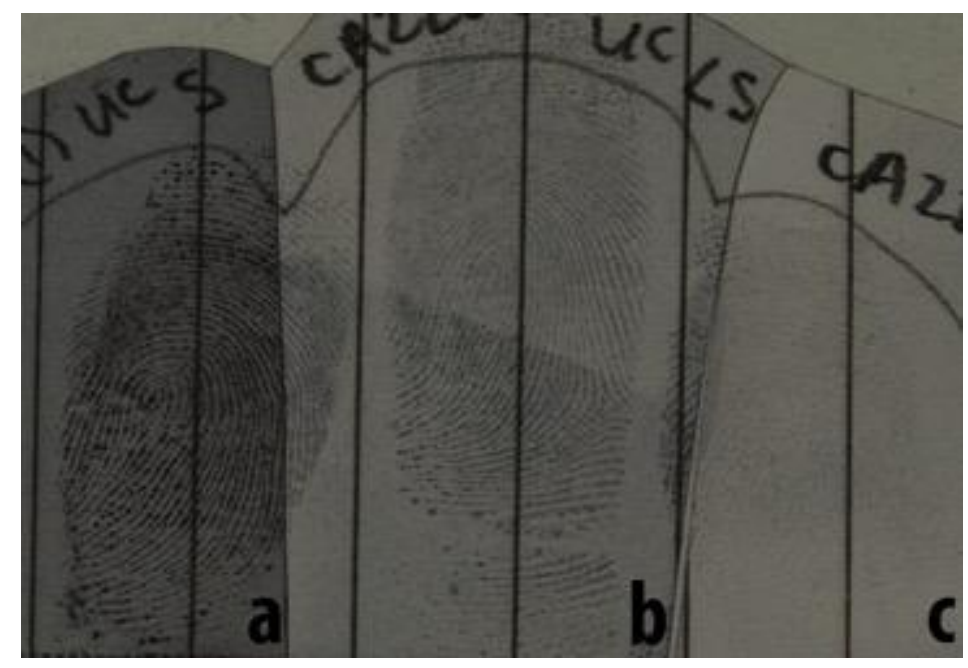

Figure7: Latent fingermarks developed on Nu World Stone Paper using SMD II with both active solution baths under (a) constant agitation, (b) minimal agitation, (c) no agitation.

No agitation of the solution baths resulted in very low levels of development and contrast, with the majority of fingermark samples achieving a grade of 0 . Minimal agitation of both solution baths throughout the fingermark submersion time resulted in higher levels of development, but produced very patchy distribution of contrast. This could be due to the overlapping of samples in the solutions, but it could also be hypothesised that it is caused by the lack of a constant gold supply to certain areas of the sample; gold that is deposited onto the fingermark is not replenished in areas without mixing, prohibiting a constant supply of gold for deposition onto the sample. The majority of these samples produced a grade of 2 . When both the gold nanoparticle solution bath and the reduction solution bath were under constant agitation for the entire submersion time, higher levels of development were achieved with even distribution of contrast throughout the fingermark samples, resulting in most samples being graded at a 3 . To investigate the dependency of higher levels of fingermark development on the agitation of the individual solution baths, a trial was done in which only the gold nanoparticle solution bath was under constant agitation for the submersion time and the reduction bath was left untouched. This was compared to samples that underwent the process with both solution baths under constant agitation, as illustrated in Figure 8. 


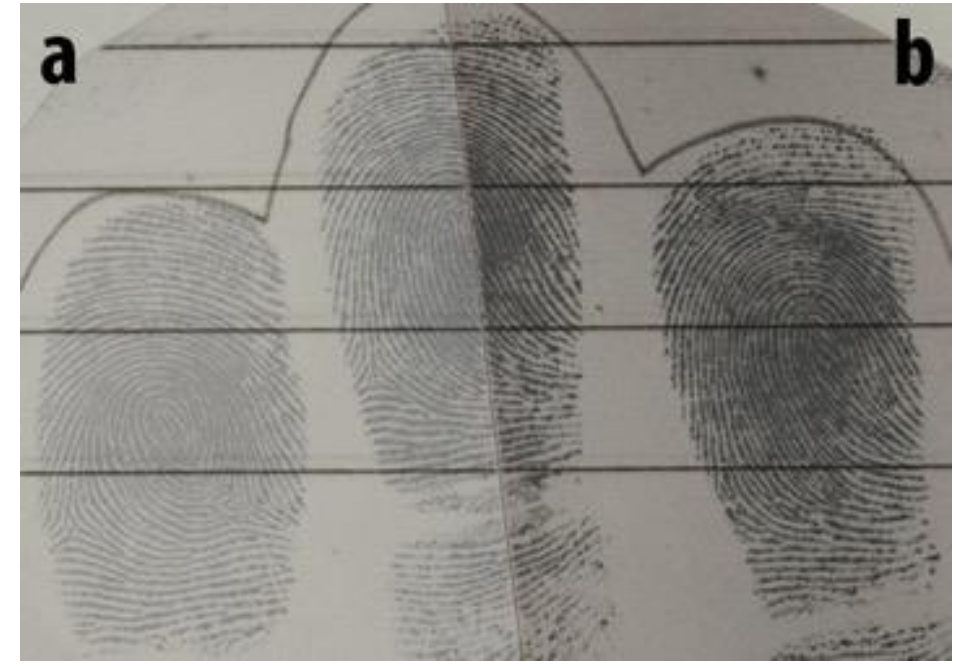

Figure 8: Latent fingermarks developed on Nu World Stone Paper using SMD II with (a) only the gold nanoparticle solution bath under constant shaking and (b) both active solution baths under constant shaking.

Higher levels of fingermark ridge detail development appear to be primarily dependent on the constant agitation of the gold nanoparticle solution bath, as the majority of samples from both trials achieved the same grade of 2 . The contrast obtained by the fingermarks processed under constant agitation of both solution baths, however, is much greater. This is evident when comparing the resulting median of 2.5 to a median of 2 for samples processed with only the nanoparticle bath under constant agitation. The level of fingermark development achieved is therefore affected by the deposition of gold nanoparticles onto the fingermark residue, while the degree of contrast is influenced by the reduction of gold onto the deposited nanoparticles. This result is consistent with the findings of Durussel et al. on SMD I (15).

\subsection{Operational substrates experimentation}

The SMD II procedure was applied to latent fingermarks on a range of different substrates to test its efficacy. A summary of the achieved fingermark grades on these various surfaces is listed in Table 5, along with a categorisation of the type of fingermark development obtained on each surface. 
Table 5: Grading and fingermark development data obtained on a range of different substrates tested using SMD II.

\begin{tabular}{|c|c|c|}
\hline Substrate & $\begin{array}{c}\text { Most common } \\
\text { fingermark grade }\end{array}$ & Contrast obtained \\
\hline OfficeMax ${ }^{\circledast}$ recycled white copy paper & 3 & Dark ridges \\
\hline Nu World ${ }^{\circledR}$ Stone Paper & 4 & Dark ridges \\
\hline White Post It ${ }^{\circledR}$ note & 1 & Dark ridges \\
\hline $\mathrm{HP}^{\circledR}$ matte photo paper & 2 & Dark ridges \\
\hline Optix ${ }^{\circledR}$ green copy paper & 4 & Dark ridges \\
\hline Marbig ${ }^{\circledR}$ polypropylene document sleeve & 3 & $\begin{array}{c}\text { Dark ridges, with light gold } \\
\text { plating of background }\end{array}$ \\
\hline Fuji Xerox ${ }^{\circledR}$ white copy paper & 1 & $\begin{array}{c}\text { Dark ridges, with heavy } \\
\text { purple background } \\
\text { staining }\end{array}$ \\
\hline Confoil $^{\circledR}$ aluminium foil & 2 & White ridges \\
\hline $\begin{array}{l}\text { Glossy white paper from International Association } \\
\text { for Identification's "IDentification News" newsletter }\end{array}$ & 2 & White ridges \\
\hline Polymethyl methacrylate white car paint & 4 & $\begin{array}{l}\text { White ridges, with heavy } \\
\text { gold plating of background }\end{array}$ \\
\hline Polycarbonate Lite-On ${ }^{\circledR}$ Compact Disk & 4 & $\begin{array}{l}\text { White ridges, with light } \\
\text { gold plating of background }\end{array}$ \\
\hline Optix ${ }^{\circledR}$ black cardboard & 1 & Gold ridges \\
\hline Patterned wrapping paper & 3 & Gold ridges \\
\hline Curtin University cardboard document wallet & 1 & $\begin{array}{l}\text { Dark ridges, with damage } \\
\text { to substrate }\end{array}$ \\
\hline Gormack Graph Papers ${ }^{\circledR}$ ruled graph paper & 1 & $\begin{array}{l}\text { Dark ridges, with damage } \\
\text { to substrate }\end{array}$ \\
\hline Olympic ${ }^{\circledR}$ thin white exercise book paper & 2 & $\begin{array}{l}\text { Dark ridges, with damage } \\
\text { to substrate }\end{array}$ \\
\hline Spank Publishing ${ }^{\circledR}$ thick white notebook paper & 1 & $\begin{array}{l}\text { Dark ridges, with damage } \\
\text { to substrate }\end{array}$ \\
\hline Polyethylene Kartell ${ }^{\circledR}$ laboratory bottle & 1 & Reversed development \\
\hline $\begin{array}{l}\text { Polyethylene terephthalate Cool Ridge }{ }^{\circledR} \text { water } \\
\text { bottle }\end{array}$ & 2 & Reversed development \\
\hline Polypropylene takeaway container & 1 & Reversed development \\
\hline Mikro ${ }^{\circledR}$ glass microscope slide & 1 & Reversed development \\
\hline Coke Zero $^{\circledR}$ aluminium can & 1 & No visible ridge detail \\
\hline $\begin{array}{l}\text { White paper from American Academy of Forensic } \\
\text { Sciences' "Academy News" newsletter }\end{array}$ & 1 & No visible ridge detail \\
\hline
\end{tabular}

An example of each of these individual categories of fingermarks obtained is illustrated in Table 6 below. Samples that have been categorised under 'dark ridges' allowed for the visualisation of an expected dark grey coloured fingermark on their surface, while samples 
labelled as 'white ridges' and 'gold ridges' resulted in white or gold coloured fingermarks on their respective surfaces in a similar fashion.

Table 6: Examples of fingermarks developed using SMDII on a range of different surfaces.

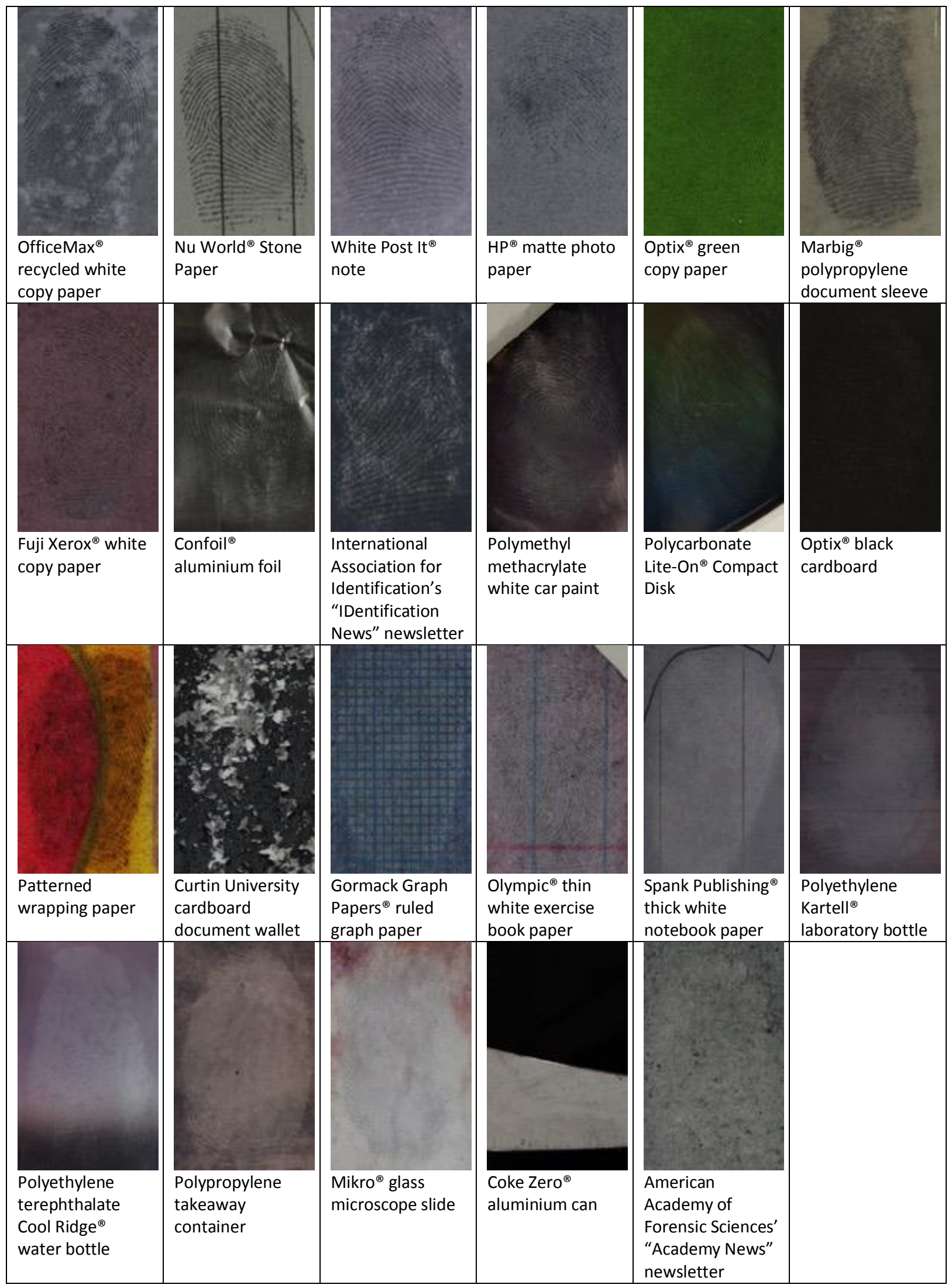


The majority of the 'white ridge' fingermarks obtained were on surfaces that experienced a significant degree of background staining, or in some cases gold plating, such as on the polymethyl methacrylate white car paint sample. The 'gold ridge' fingermark illustrated on the wrapping paper surface is a very significant result, as attempts at latent fingermark detection on this substrate using techniques such as Nile blue and Oil Red $O$ have been unsuccessful due to both the smooth, glossy material and the various bright colours and patterns covering the surface $(36,37)$. A small number of substrates experienced a degree of damage throughout the SMD II procedure due to the long immersion time in water as well as the acidic conditions of the gold nanoparticle solution bath $(\mathrm{pH} 2.40)$, although they still resulted in visible fingermark development, such as that obtained on the thin exercise book paper. Finally, samples categorised as 'reversed development' appeared to experience heavy pink background staining of the substrate yet no staining of the fingermark ridges, generally resulting in the so-called reverse fingermark, or in some cases a blank space where the fingermark was situated. A similar phenomenon has been noted on paper surfaces when using gold nanoparticles modified to specifically target the cellulose substrate $(38,39)$. In this work we did not observe reversed or "empty" developed marks on paper, which is not surprising as the gold nanoparticles were not modified as those in the earlier work by Almog and co-workers. In a similar fashion this phenomenon has been observed through when using vacuum metal deposition (VMD) for latent fingermark detection, with reverse fingermarks being obtained on low-density polyethylene surfaces (40-42). The deposition of zinc onto the fingermark residues rather than the substrate is suggested to be due to the plastic surface absorbing the organic constituents of the fingermark residues, leaving behind a solid inorganic material that is less permeable to the gold than the plastic (43). Alternatively, it has been proposed that the unusual result may be produced by interactions between the substrate and gold layer, leaving the gold unable to act as a viable nucleation site for zinc deposition (40). While the mechanism of SMD II is currently undetermined, these suggestions regarding VMD can potentially also explain the reversed development obtained on plastic surfaces through the use of SMD II. In recent studies using atomic force microscopy we observed the propagation of thin films $(0.2-1.1 \mathrm{~nm}$ in thickness) of material across the furrows of latent fingermarks deposited on glass over the first 24 hours after deposition (44). We postulated that this may also contribute to the "reverse" development encountered in VMD, and that may also be the case here.

These diverse results are clearly dependent on the properties of the substrate and their interactions with the gold nanoparticles; however, without knowing how the method operates to target the latent fingermark residue, it is difficult to explain the production of these fingermarks with various appearances. To gain an idea of why certain substrates interact with the gold nanoparticles and others do not, it is important to acquire an understanding of the mechanism behind the development technique (4). Regardless of the type of fingermark visualisation obtained, the SMD II procedure is clearly applicable to a wide range of substrates, including porous, non-porous, and semi-porous surfaces. It has 
also proven to be successful for latent fingermark detection on substrates such as wrapping paper that are difficult surfaces known to result in poor fingermark visualisation using a range of differing development procedures.

\section{Conclusions}

The purpose of this study was to investigate single metal deposition (SMD) II as a latent fingermark detection technique from an operational point of view. Gold nanoparticles of different diameters were synthesised by altering the length of the boiling time of gold salt in water prior to adding the reducing agents; larger nanoparticles than desired can be obtained by minimising the boiling time, while much smaller nanoparticles are produced through extended boiling time. After experimentation with a range of different gold nanoparticle sizes, solution temperatures, and levels of agitation, it was found that optimal development of fingermarks using SMD II was achieved through the use of red-coloured gold nanoparticle stock solutions containing nanoparticles of approximate diameter 15$21 \mathrm{~nm}$, applied to fingermarks at room temperature $\left(20-25^{\circ} \mathrm{C}\right)$, with both the gold nanoparticle solution bath and the reduction bath under constant agitation throughout the entire submersion time. These parameters are consistent with those published, validating that the SMD II technique does not appear to be dependent on the geographic location. While the procedure's efficacy was sensitive to all of these conditions, satisfactory levels of development can still be achieved with slight variation of these parameters, demonstrating the robustness of the method and its associated suitability for operational use. The procedure was shown to be effective on a large range of porous, non-porous, and semiporous substrates, including previously difficult surfaces that are known to hinder latent fingermark development when using various other detection techniques. The properties of each substrate had a significant effect on the appearance of the development obtained, allowing for the production of a range of visually different fingermarks, some of which have been similarly observed with the use of other detection methods such as vacuum metal deposition $(40,41)$.

\section{Acknowledgements}

The authors thank all of the fingermark donors who participated in this study, as well as Rhys Tilbury (Curtin University) for his valuable assistance and discussions during the course of the research. We thank Dr Daniel Southam (Curtin University) for designing and producing the graphical abstract. Ethics approval was granted prior to fingermark collection by the Curtin University Human Research Ethics Committee (approval number SMEC-47-13). This research did not receive any specific grant from funding agencies in the public, commercial, or not-for-profit sectors. 


\section{References}

1. Bécue A, Cantu AA. Fingermark Detection Using Nanoparticles. In: Ramotowski R, editor. Lee and Gaensslen's Advances in Fingerprint Technology. 3rd ed: CRC Press; 2012. p. 307-48.

2. Dilag J, Kobus HJ, Ellis AV. Nanotechnology as a New Tool for Fingermark Detection: A Review. Current Nanoscience. 2011;7(2):153-9.

3. Hazarika P, Russell DA. Advances in Fingerprint Analysis, International Edition. Angewandte Chemie. 2012;51:3524-31.

4. Moret S, Becue A, Champod C. Nanoparticles for fingermark detection: an insight into the reaction mechanism. Nanotechnology. 2014;25(42):425502.

5. Li MD, Cheng TL, Tseng WL. Nonionic surfactant-capped gold nanoparticles for selective enrichment of aminothiols prior to CE with UV absorption detection. Electrophoresis. 2009;30(2):388-95.

6. Ivanov MR, Bednar HR, Haes AJ. Investigations of the mechanism of gold nanoparticle stability and surface functionalization in capillary electrophoresis. ACS Nano. 2009;3(2):386-94. 7. Verma HN, Singh P, Chavan RM. Gold nanoparticle: synthesis and characterization. Veterinary World. 2014;7(2):72-7.

8. Bécue A, Scoundrianos A, Champod C, Margot P. Fingermark detection based on the in situ growth of luminescent nanoparticles--towards a new generation of multimetal deposition. Forensic Science International. 2008;179(1):39-43.

9. Liu X, Atwater M, Wang J, Huo Q. Extinction coefficient of gold nanoparticles with different sizes and different capping ligands. Colloids and Surfaces B: Biointerfaces. 2007;58(1):3-7.

10. Wang A, Ng HP, Xu Y, Li Y, Zheng Y, Yu J, et al. Gold Nanoparticles: Synthesis, Stability Test, and Application for the Rice Growth. Journal of Nanomaterials. 2014;2014:1-6.

11. Bécue A, Moret S, Champod C, Margot P. Use of stains to detect fingermarks. Biotechnic \& Histochemistry. 2011;86(3):140-60.

12. Bécue $A$, Scoundrianos A, Moret $S$. Detection of fingermarks by colloidal gold (MMD/SMD)-beyond the $\mathrm{pH} 3$ limit. Forensic Science International. 2012;219(1-3):39-49.

13. Stauffer E, Bécue A, Singh KV, Thampi KR, Champod C, Margot P. Single-metal deposition (SMD) as a latent fingermark enhancement technique: an alternative to multimetal deposition (MMD). Forensic Science International. 2007;168(1):e5-9.

14. Fairley C, Bleay SM, Sears VG, NicDaeid N. A comparison of multi-metal deposition processes utilising gold nanoparticles and an evaluation of their application to 'low yield' surfaces for finger mark development. Forensic Science International. 2012;217(1-3):5-18.

15. Durussel P, Stauffer E, Bécue A, Champod C, Margot P. Single-Metal Deposition: Optimization of this Fingermark Enhancement Technique. Journal of Forensic Identification. 2009;59(1):80-96.

16. Bécue A, Moret S. Single-Metal Deposition for Fingermark Detection-A Simpler and More Efficient Protocol. Journal of Forensic Identification. 2015;65(2):118-37.

17. Bécue A. Les nanoparticules, une nouvelle arme contre le crime? L'Actualité Chimique 2010;342-343.

18. (IFRG) IFRG. Guidelines for the Assessment of Fingermark Detection Techniques. Journal of Forensic Identification. 2014;64(2):174-200.

19. Spindler $X$, Shimmon R, Roux $C$, Lennard C. The effect of zinc chloride, humidity and the substrate on the reaction of 1,2-indanedione-zinc with amino acids in latent fingermark secretions. Forensic Science International. 2011;212(1-3):150-7.

20. Bicknell DE, Ramotowski RS. Use of an optimized 1,2-indanedione process for the development of latent prints. Journal of Forensic Sciences. 2008;53(5):1108-16. 
21. Wallace-Kunkel C, Lennard C, Stoilovic M, Roux C. Optimisation and evaluation of 1,2indanedione for use as a fingermark reagent and its application to real samples. Forensic Science International. 2007;168(1):14-26.

22. Switzerland M. Climate Switzerland: Switzerland Tourism; 2015 [Available from: http://www.myswitzerland.com/en-au/climate.html.

23. Switzerland SI. Climate of Switzerland Switzerland: Swiss Universities' International Marketing (SUIM); 2015 [Available from: http://www.studyinginswitzerland.ch/country-climate.htm.

24. Australia Co. Australian Climate Influences Australia: Australian Government; 2010

[Available from: http://www.bom.gov.au/climate/about/?bookmark=introduction.

25. Australia T. Weather in Perth Australia: Australia.com; 2015 [Available from:

http://www.australia.com/en/facts/weather/perth-weather.html.

26. Kent T. Standardizing protocols for fingerprint reagent testing. Journal of Forensic Identification. 2010;60(3):371-9.

27. Sears VG, Bleay SM, Bandey HL, Bowman VJ. A Methodology for Finger Mark Research. Science \& Justice. 2012;52:145-60.

28. Bandey HL, Bleay SM, Gibson AP, editors. Powders for fingerprint development 2013 CRC Press

29. Fritz $\mathrm{P}$, Van Bronswijk W, Patton E, Lewis SW. Variability in visualization of latent fingermarks developed with 1,2-indanedione / zinc chloride. Journal of Forensic Identification. 2013;63(6):698-

713.

30. Bac LH, Kim JS, Kim JC. Size, Optical and Stability Properties of Gold Nanoparticles Synthesized by Electrical Explosion of Wire in Different Aqueous Media. Reviews on Advanced Materials Science. 2011;28:117-21.

31. Berciaud S, Cognet L, Tamarat $P$, Lounis B. Observation of intrinsic size effects in the optical response of individual gold nanoparticles. Nano Letters. 2005;5(3):515-8.

32. Sattler KD. Nanoelectronics and Nanophotonics: CRC Press; 2010.

33. Huang X, El-Sayed MA. Gold nanoparticles: Optical properties and implementations in cancer diagnosis and photothermal therapy. Journal of Advanced Research. 2010;1(1):13-28.

34. Roduner E. Size matters: why nanomaterials are different. Chemical Society Reviews. 2006;35(7):583-92.

35. Schnetz B, Margot P. Technical note: latent fingermarks, colloidal gold and multimetal deposition (MMD) - Optimisation of the method. Forensic Science International. 2001;118:21-8.

36. Frick AA, Fritz $P$, Lewis SW, van Bronswijk W. A modified Oil Red O reagent for the detection of latent fingermarks on porous substrates Journal of Forensic Identification 2012

37. Frick AA, Busetti F, Cross A, Lewis SW. Aqueous Nile blue: a simple, versatile and safe reagent for the detection of latent fingermarks. Chemical Communications. 2014;50:3341-3.

38. Jaber N, Lesniewski A, Gabizon H, Shenawi S, Mandler D, Almog J. Visualization of Latent Fingermarks by Nanotechnology: Reversed Development on Paper-A Remedy to the Variation in Sweat Composition. Angewandte Chemie International Edition. 2012;51(49):12224-7.

39. Shenawi S, Jaber N, Almog J, Mandler D. A novel approach to fingerprint visualization on paper using nanotechnology: reversing the appearance by tailoring the gold nanoparticles' capping ligands. Chemical Communications. 2013;49(35):3688-90.

40. Jones N, Stoilovic M, Lennard C, Roux C. Vacuum metal deposition: factors affecting normal and reverse development of latent fingerprints on polyethylene substrates. Forensic Science International. 2001;115:73-88.

41. Jones N, Mansour D, Stoilovic M, Lennard C, Roux C. The influence of polymer type, print donor and age on the quality of fingerprints developed on plastic substrates using vacuum metal deposition. Forensic Science International. 2001;124(2-3):167-77.

42. Jones N, Stoilovic M, Lennard C, Roux C. Vacuum metal deposition developing latent fingerprints on polyethylene substrates after the deposition of excess gold. Forensic Science International. 2001;123(1):5-12. 
43. Kent T, Thomas GL, Reynoldson TE, East HW. A Vacuum Coating Technique for the Development of Latent Fingerprints on Polythene. Journal of the Forensic Science Society. 1976;16(2):93-101.

44. Dorakumbura BN, Becker T, Lewis SW. Nanomechanical mapping of latent fingermarks: A preliminary investigation into the changes in surface interactions and topography over time.

Forensic Science International. 2016;267:16-24. 